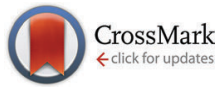

Cite this: Chem. Commun., 2015, 51,2660

Received 1st August 2014 Accepted 19th December 2014

DOI: $10.1039 / \mathrm{c} 4 \mathrm{cc} 06021 \mathrm{k}$

www.rsc.org/chemcomm

\section{A high-throughput screening method for determining the substrate scope of nitrilases $\dagger$}

\author{
Gary W. Black, ${ }^{a}$ Nicola L. Brown, ${ }^{a}$ Justin J. B. Perry, ${ }^{* a}$ P. David Randall, ${ }^{b}$ \\ Graeme Turnbull ${ }^{a}$ and Meng Zhang ${ }^{a}$
}

\begin{abstract}
Nitrile compounds are intermediates in the synthesis of pharmaceuticals such as atorvastatin. We have developed a chromogenic reagent to screen for nitrilase activity as an alternative to Nessler's reagent. It produces a semi-quantifiable blue colour and hydrolysis of 38 nitrile substrates by 23 nitrilases as cell-free extracts has been shown.
\end{abstract}

Nitrile compounds $(\mathrm{R}-\mathrm{C} \equiv \mathrm{N})$ are useful intermediates in the synthesis of fine chemicals and pharmaceuticals such as atorvastatin, ${ }^{1}$ however chemical hydrolysis of these compounds usually requires harsh conditions, such as extremes of $\mathrm{pH}$ and high temperatures ${ }^{2}$ with the creation of significant quantities of byproducts. ${ }^{3}$ Biocatalytic hydrolysis is seen as a viable 'green' alternative for the production of these acids as it can be conducted at near-ambient temperature and neutral $\mathrm{pH}^{3,4}$ Nitrile-hydrolysing enzymes typically display enantioand regioselectivity that simply cannot be achieved through chemical hydrolysis. ${ }^{3,5-7}$ There are two classes of nitrile-hydrolysing enzymes: nitrile hydratases (EC 4.2.1.84) which convert nitrile functionality to primary amides; ${ }^{8}$ and nitrilases (EC 3.5.5.1) which convert nitriles to the related carboxylic acid. ${ }^{9}$

The pace of development of novel biocatalytic processes has increased with advances in genomics, laboratory-based evolution and protein expression, ${ }^{10-12}$ however this is limited by the rate at which new enzymes can be screened for activity and substrate specificity. Methods of screening nitrilase activity in whole cells typically involve cell culture in the presence of a range of nitrile substrates and measurement of products by chromatographic methods such as LC- or GC-MS. ${ }^{13}$ Due to the time-consuming nature of such work, substrate ranges are often limited to a handful of nitrile types. Other spectroscopic techniques such as NMR and IR spectroscopy have also found use for kinetic assays, but not for high-throughput applications. ${ }^{14}$ While published reviews compare substrate specificity for some organisms, these results are obtained

\footnotetext{
${ }^{a}$ Industrial Biotechnology Research Group, Department of Applied Sciences, Faculty of Health and Life Sciences, Northumbria University,

Newcastle upon Tyne, NE1 8ST, UK. E-mail: justin.perry@northumbria.ac.uk

${ }^{b}$ Chemoxy International Ltd, Middlesbrough, Cleveland, TS3 6AF, UK

$\dagger$ Electronic supplementary information (ESI) available. See DOI: 10.1039/c4cc06021k
}

through different experimental conditions making close comparison difficult. ${ }^{4,10,15}$

Several high-throughput assays for nitrilase activity have been developed, including the use of $\mathrm{pH}$ indicators ${ }^{16}$ or formation of a chromophore $^{17}$ to measure acid generation and the formation of a chromophore or fluorophore to measure ammonia generation, ${ }^{18}$ however in each case activity is measured using whole live cells or purified enzymes. The use of lyophilised cleared cell lysates (usually referred to as cell-free extracts, CFEs) provides a convenient way of screening potential new nitrilases for substrate specificity without the need for enzyme purification, however current rapid screening methods are incompatible with cellular components present in CFE solutions. Here we present a facile and inexpensive high-throughput method for the screening of nitrilase-containing CFE libraries against a wide range of nitrile substrates, which utilises the chromogenic reaction between $o$-phthalaldehyde (OPA, 1) and ammonia under acid-catalysed conditions (Scheme 1), and report its use to indicate the substrate preferences of a library of nitrilases against a range of structurally-diverse substrates.

Banerjee et al. have reported a method that utilises $\mathbf{1}$ in the presence of mercaptoethanol to generate a fluorescent product. ${ }^{19} \mathrm{We}$ found this method to be incompatible with CFE as it generated high background fluorescence. The formation of chromogenic products in the reaction between ammonia and $\mathbf{1}$ in the absence of thiol reducing agents is well known, ${ }^{20}$ and accounts exist as far back as the early twentieth century. ${ }^{21,22}$ The products of this reaction are

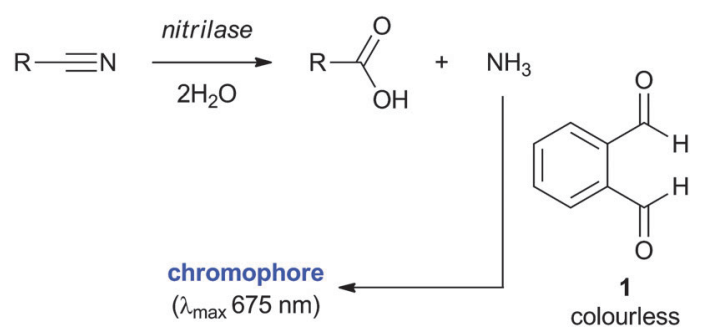

Scheme 1 Nitrilase hydrolyses nitrile compounds to the corresponding carboxylic acid and ammonia. The ammonia reacts with $\mathbf{1}$ in our reagent to generate a blue chromophore. 
known to be unstable ${ }^{23}$ and are thought to be the result of several competing reactions occurring in parallel, ${ }^{22,24,25}$ though an isoindole species is believed to be the most abundant product. Despite this lack of clarity regarding the nature of the chromophoric species, it can be shown to be suitable to form the basis of an ammoniadetecting assay suitable for semi-quantitatively measuring nitrilase activity. Reaction of $\mathbf{1}$ with ammonia in basic buffer forms a colourless intermediate species, which on acidification becomes intensely coloured. The hue depends on the acid used and ranges from light blue to deep purple in colour (Fig. S1, ESI $\dagger$ ), however trichloroacetic acid (TCA) was found to give the greatest contrast as a blue-black chromophore is formed. This chromophore can precipitate on standing, however dilution with DMSO yields a blue species that is suitable for quantitative measurement by UV/visible spectroscopy. Using a set of standard $\mathrm{NH}_{4} \mathrm{Cl}$ solutions it was shown that quantitation of the ammonia over the range 1-11 $\mathrm{mM}$ was possible $\left(R^{2}=0.999\right)$ enabling nitrilase assays to be designed which yield ammonia in this concentration range (Fig. 1).

To demonstrate the utility of this detection method for determination of nitrilase activity, this screening method was used to determine the substrate specificity and relative activity for a range of twenty-three nitrilases recombinantly expressed in Escherichia coli (18 were rationally sampled from the diversity that exists within sequence space [Fig. S3, ESI $\dagger$ ] , and five were commercially available through Prozomix Ltd, UK) and stored as lyophilised CFEs (all entries are provided in the ESI, $\uparrow$ Tables S1 and S2).

Solutions of these CFEs were prepared in phosphate buffer (10 mM, pH 7.2), combined with a structurally-diverse panel of thirty-eight aliphatic, aromatic and arylaliphatic nitrile compounds (Fig. 2, prepared in EtOH or DMSO to aid solubility) in 96-well microplates and incubated overnight $\left(37^{\circ} \mathrm{C}, 18 \mathrm{~h}\right)$. OPA reagent was prepared as a solution of 1 in methanol and diluted 1:100 into sodium tetraborate buffer $(15 \mathrm{mM}, \mathrm{pH}$ 9.5). This reagent was combined with the incubated mixture, added to DMSO and acidified with TCA solution (aq. 10\% w/v) to yield a blue-black chromogen in proportion to the ammonia liberated by the nitrilasecatalysed hydrolysis in each well. These solutions were further diluted with DMSO to enable concentration determination by UV/visible spectroscopy using a standard curve for calibration. An example of a microplate containing an assay of this type is shown in Fig. 3. Nine of the 23 enzymes hydrolyse one or more of these substrates at the level of $\geq 20 \%$ conversion. Of these active enzymes, five (entries 2-4, 6-7) are predominantly arylacetonitrilases and four (entries 1, 5, 19 and 22) are predominantly aromatic nitrilases. Promiscuity is however observed across the range, with entries 4 and 19 most active for the widest range of

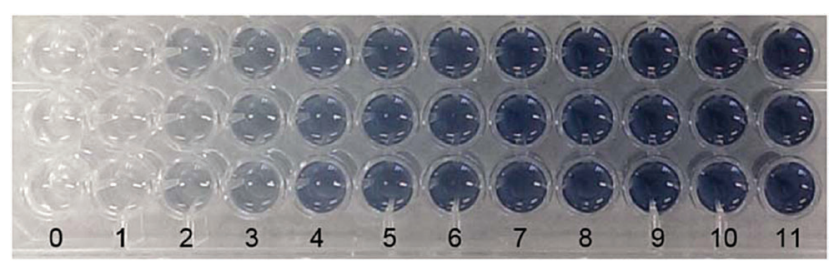

Fig. 1 Reaction of OPA reagent with ammonia (concentration of $\mathrm{NH}_{4} \mathrm{Cl}$ standard solution in $\mathrm{mM}$ indicated as number) after dilution with DMSO.

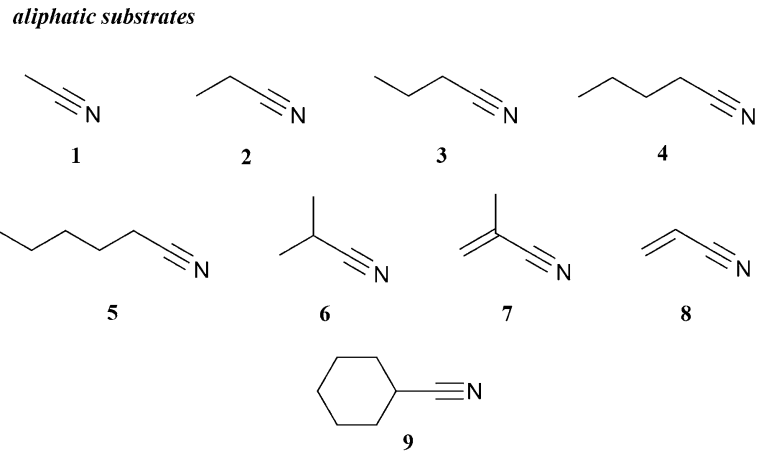

aromatic substrates<smiles>N#Cc1ccccc1</smiles><smiles>N#Cc1ccccc1O</smiles><smiles>Cc1ccccc1C#N</smiles><smiles>Cc1ccc(C#N)cc1</smiles><smiles>COc1ccc(C#N)cc1</smiles><smiles>CN(C)c1ccc(C#N)cc1</smiles><smiles>CC(C)c1cc(N(C)C)cc(C(C)C)c1C#N</smiles><smiles>N#Cc1ccc(N)cc1</smiles><smiles>N#Cc1ccccn1</smiles><smiles>N#Cc1cccnc1</smiles><smiles>N#Cc1ccncc1</smiles>

arylaliphatic substrates<smiles>N#CCc1ccccc1</smiles><smiles>N#CCc1ccc([N+](=O)[O-])cc1</smiles><smiles>N#CCc1ccccc1Cl</smiles><smiles>N#CCc1ccccc1[N+](=O)[O-]</smiles><smiles>N#CCc1c(Cl)cccc1Cl</smiles><smiles>N#CCC(=O)c1ccccc1</smiles><smiles>CC(C#N)c1ccccc1</smiles><smiles>CC(C)Cc1ccc(C(C)C#N)cc1</smiles><smiles>N#CC(c1ccccc1)c1ccccc1</smiles>

35<smiles>N#CCc1ccc2ccccc2c1</smiles><smiles>N#CCCc1ccccc1</smiles>

36

37

Fig. 2 Nitrile substrates used to screen each nitrilase CFE.

substrates. Six highly active nitrilases are immediately obvious from these results, with the Bradyrhizobium spp. 3 and $\mathbf{4}$ displaying up to $100 \%$ conversion of 2-phenylacetonitrile. 


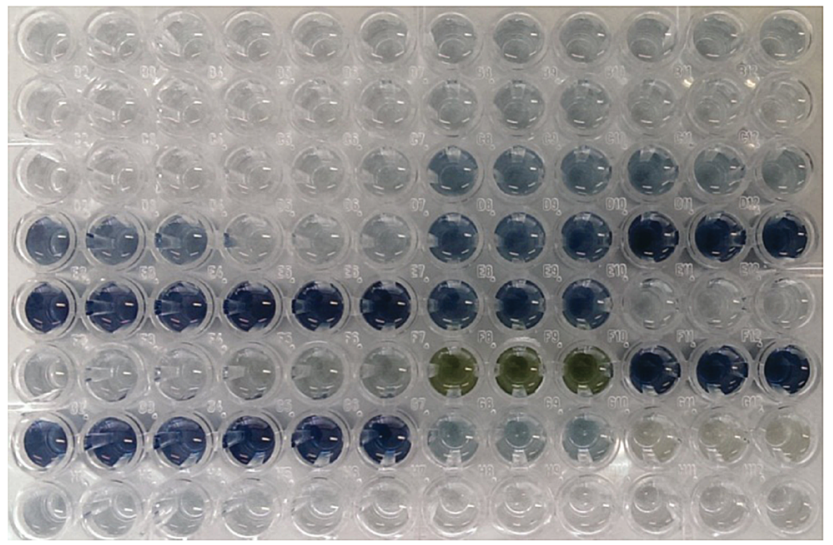

Fig. 3 Reaction of OPA reagent with nitrilase 5 CFE solution after incubation with nitrile substrates 1-31 in triplicate (see Fig. S2, ESI† for full details).

Nitrilases from Chaetomium globosum (5) and PRO-NITR010 (19) have an obvious preference for 4-substituted aromatic nitrile compounds, while these and PRO-NITR014 (22) display high activity towards pyridinecarbonitriles.

Nitrilases from species Bradyrhizobium sp. BTAi1 (A5ETE9; 8), Rhodopseudomonas palustris (Q2J474; 9), Silicibactor promeroyi (Q5LLB2; 10), PRO-NITR012 (21), and PRO-NITR018 (23) displayed very weak activity against the substrate panel $(<20 \%$ substrate hydrolysed). Nitrilases from species Achromobacter xylosoxidans (E3HN55), Acidovorax avenae (F0Q9Y1), Alcaligenes faecalis (G8CXY5), Bacillus cereus (Q819F0), Clostridium kluyveri (A5MYU1), Lachancea thermotolerans (C5DH06), Sphaerobacter thermophilus (D1C8L7) and Vanderwaltozyma polyspora (A7TP07) (entries 11-18 respectively) displayed no detectable activity against the substrate panel ( $<10 \%$ substrate hydrolysed).

Three CFEs (entries 3, 6 and 10) were screened in duplicate from separately prepared cultures. While determination of substrate preference was repeatable the absolute conversion was not identical, highlighting a disadvantage of using CFEs over purified enzymes where activity per gramme is a tightly defined value in comparison to culture-dependent variation which is inherent in analysis of CFEs.

As additional confirmation of the efficacy of our screen for the detection of nitrilase activity, a comparison was made between levels of ammonia detected by the established Nessler method and by OPA reagent. Solutions of four active CFEs (entries 3a, 5, 19 and 22) were rescreened against twenty-nine structurally diverse substrates and the ammonia concentrations determined by both Nessler's reagent (Sigma Aldrich) and OPA reagent.§ Comparison of the concentrations of ammonia for 23 of these substrates shows a significant correlation (Spearman rank correlation, $\rho(23)=0.995,0.910,0.603$ and 0.962 respectively; $P \leq 0.002$ ). Comparison was not possible for a further six substrates as a precipitate was formed in the Nessler solutions with some CFEs.

The use of $o$-phthalaldehyde to determine nitrilase activity of crude cell-free extracts has been demonstrated, and been used to determine selectivity of a panel of enzymes against a wide variety of nitrile substrates in a simple, high-throughput method compatible with using a microplate reader. The ability to screen in such small volumes provides a fast and economical way of experimentally identifying new nitrilase enzymes, and rapidly ascertain their substrate specificity. In comparison to the existing Nessler assay, this reagent is free of mercury salts and is not persistent in the environment.

We wish to extend our thanks to Dr Simon Charnock of Prozomix Ltd for providing the commercially available nitrilases used in this screen, to Biocatalysts Ltd for their collaboration and to the Technology Strategy Board for funding.

\section{Notes and references}

$\$$ Confirmatory tests indicating the presence of carboxylic acid after nitrile hydrolysis were performed using HPLC and GC-MS.

$\S$ Experimental data is included in the ESI.

1 U. T. Bornscheuer, G. W. Huisman, R. J. Kazlauskas, S. Lutz, J. C. Moore and K. Robins, Nature, 2012, 485, 185-194.

2 M. Kobayashi and S. Shimizu, Curr. Opin. Chem. Biol., 2000, 4, 95-102.

3 A. Banerjee, R. Sharma and U. C. Banerjee, Appl. Microbiol. Biotechnol., 2002, 60, 33-44.

4 R. N. Thuku, D. Brady, M. J. Benedik and B. T. Sewell, J. Appl. Microbiol., 2009, 106, 703-727.

5 F. B. Cooling, S. K. Fager, R. D. Fallon, P. W. Folsom, F. G. Gallagher, J. E. Gavagan, E. C. Hann, F. E. Herkes, R. L. Phillips, A. E. Sigmund, L. W. Wagner, W. Wu and R. DiCosimo, J. Mol. Catal. B: Enzym., 2001, 11, 295-306.

6 F. Effenberger and S. Oßwald, Synthesis, 2001, 1866-1872.

7 D. E. Robertson, J. A. Chaplin, G. DeSantis, M. Podar, M. Madden, E. Chi, T. Richardson, A. Milan, M. Miller, D. P. Weiner, K. Wong, J. McQuaid, B. Farwell, L. A. Preston, X. Tan, M. A. Snead, M. Keller, E. Mathur, P. L. Kretz, M. J. Burk and J. M. Short, Appl. Environ. Microbiol., 2004, 70, 2429-2436.

8 S. van Pelt, M. Zhang, L. G. Otten, J. Holt, D. Y. Sorokin, F. van Rantwijk, G. W. Black, J. J. Perry and R. A. Sheldon, Org. Biomol. Chem., 2011, 9, 3011-3019.

9 L. Martínková and V. Křen, Curr. Opin. Chem. Biol., 2010, 14, 130-137.

10 J.-S. Gong, Z.-M. Lu, H. Li, J.-S. Shi, Z.-M. Zhou and Z.-H. Xu, Microb. Cell Fact., 2012, 11, 142.

11 G. DeSantis, K. Wong, B. Farwell, K. Chatman, Z. Zhu, G. Tomlinson, H. Huang, X. Tan, L. Bibbs, P. Chen, K. Kretz and M. J. Burk, J. Am. Chem. Soc., 2003, 125, 11476-11477.

12 G. DeSantis, Z. Zhu, W. A. Greenberg, K. Wong, J. Chaplin, S. R. Hanson, B. Farwell, L. W. Nicholson, C. L. Rand, D. P. Weiner, D. E. Robertson and M. J. Burk, J. Am. Chem. Soc., 2002, 124, 9024-9025.

13 A. Banerjee, P. Kaul and U. C. Banerjee, Arch. Microbiol., 2006, 184, 407-418.

14 L. Martínková, V. Vejvoda and V. Křen, J. Biotechnol., 2008, 133, 318-326.

15 C. O'Reilly and P. D. Turner, J. Appl. Microbiol., 2003, 95, 1161-1174. 16 A. Banerjee, P. Kaul, R. Sharma and U. C. Banerjee, J. Biomol. Screening, 2003, 8, 559-565.

17 Y.-C. He, C.-L. Ma, J.-H. Xu and L. Zhou, Appl. Microbiol. Biotechnol., 2011, 89, 817-823.

18 C. Molins-Legua, S. Meseguer-Lloret, Y. Moliner-Martinez and P. Campíns-Falcó, Trends Anal. Chem., 2006, 25, 282-290.

19 A. Banerjee, R. Sharma and U. C. Banerjee, Biotechnol. Appl. Biochem., 2003, 37, 289-293.

20 S. S. Simons and D. F. Johnson, J. Org. Chem., 1978, 43, 2886-2891.

21 E. Winter, Justus Liebigs Ann. Chem., 1900, 311, 353-362.

22 L. Seekles, Recl. Trav. Chim. Pays-Bas, 1924, 93-102.

23 C. M. Hong and A. V. Statsyuk, Org. Biomol. Chem., 2013, 11, 2932-2935.

24 E. Kulla and P. Zuman, Org. Biomol. Chem., 2008, 6, 3771-3780.

25 T. Do Minh, A. L. Johnson, J. E. Jones and P. P. Senise, J. Org. Chem., 1977, 42, 4217-4221. 